\title{
Erratum: Tony Conner
}

Jim Kling

Nat. Biotechnol.26, 259, 2008; published online March 2008; corrected after print 6 June 2008

In the version of this article initially published, in paragraph 7, beginning with line 2, the author incorrectly stated that "genes and promoters" were to be used; the line should have read "DNA sequences." Also, beginning with line 6, author did not include the terms "with their natural promoters, terminators and introns," between the words "species-specific genes" and "are transferred between." Finally, also beginning on line 6, the author incorrectly used the terms "but use promoters from bacteria or other organisms." The line should have read "using standard vectors

\section{Erratum: Antivirals become a broader enterprise}

Jeffrey L Fox

Nat. Biotechnol. 25, 1395-1402; published online December 7, 2007; corrected after print 8 April 2008.

In the version of this article initially published, the name of a person quoted on p. 1399 was incorrect. The CSO of Replicor of Laval, QC, Canada, given as "Andrew Toussaint" should be "Andrew Vaillant." The error has been corrected in the HTML and PDF versions of the article.

\section{Corrigendum: Direct multiplexed measurement of gene expression with color-coded probe pairs}

윽 Gary K Geiss, Roger E Bumgarner, Brian Birditt, Timothy Dahl, Naeem Dowidar, Dwayne L Dunaway, H Perry Fell, Sean Ferree, Renee D George, Tammy Grogan, Jeffrey J James, Malini Maysuria, Jeffrey D Mitton, Paola Oliveri, Jennifer L Osborn,

Tao Peng, Amber L Ratcliffe, Philippa J Webster, Eric H Davidson \& Leroy Hood

Nat. Biotechnol. 26, 317-325 (2008); published online 17 February 2008, corrected after print 16 May 2008

In the version of this article initially published, the list of authors omitted the final author, Krassen Dimitrov, and should have read as follows:

Gary K Geiss $^{1}$, Roger E Bumgarner ${ }^{2}$, Brian Birditt ${ }^{1}$, Timothy Dahl ${ }^{1}$, Naeem Dowidar ${ }^{1}$, Dwayne L Dunaway ${ }^{1}$, H Perry Fell ${ }^{1}$, Sean Ferree ${ }^{1}$, Renee D George ${ }^{1,5}$, Tammy Grogan ${ }^{1}$, Jeffrey J James ${ }^{1}$, Malini Maysuria ${ }^{1}$, Jeffrey D Mitton ${ }^{1}$, Paola Oliveri ${ }^{3,5}$, Jennifer L Osborn ${ }^{1,5}$, Tao Peng ${ }^{2}$, Amber L Ratcliffe ${ }^{1}$, Philippa J Webster ${ }^{1}$, Eric H Davidson ${ }^{3}$, Leroy Hood ${ }^{4}$ \& Krassen Dimitrov ${ }^{4,5}$

Affiliation number five should have included his present address and thus read:

${ }^{5}$ Present addresses: Department of Genome Sciences, Box 355065, University of Washington, Seattle, Washington 98195, USA (R.D.G.), Department of Biology, University College London, Darwin Building, Gower Street, London WC1E 6BT, UK (P.O.), Department of Bioengineering, Box 355061, University of Washington, Seattle, Washington 98195, USA (J.L.O.) and Australian Institute for Bioengineering and Nanotechnology, Building 75-Cnr of College and Cooper Road, The University of Queensland, Brisbane QLD 4072 Australia (K.D.).

In addition, the following line has been added to the Author Contributions: K.D. provided the ideas and design of this technology and participated in the initial research. The errors have been corrected in the HTML and PDF versions of the article. 